\title{
Supply Chain Management Practices as a Support to Innovation in SMEs
}

\author{
Simone Regina Didonet', Guillermo Díaz ${ }^{2}$
}

\begin{abstract}
Supply chain management (SCM) is an area of increasing importance among enterprises and of growing academic interest (Mentzer and Gundlach, 2010). It is based on the concept of firms as part of multiple organizations oriented to the provision of goods and services for the final customer (Lambert and Cooper, 2000). From this perspective, several studies have verified that integration and collaboration in the supply chain can provide important benefits to the companies involved. Among these benefits are added value, the creation of efficiencies and client satisfaction (Stock, Boyer and Harmon, 2010; Chow et al, 2008), which are represented by the reduction in inventories, improvements in service delivery and quality and shorter product development cycles (Corbett, Blackburn and Wassenhove, 1999).
\end{abstract}

Keywords: supply chain management; company collaboration; client satisfaction; product cycles.

'Department of Business Administration. Faculty of Applied Social Sciences, Federal University of Parana, Brazil.

${ }^{2}$ Department of Economics and Business Organization. Faculty of Economics and Business. Universidad de Barcelona, Spain.

ISSN: 07 I8-2724. (http://www.jotmi.org)

Journal of Technology Management \& Innovation (C) Universidad Alberto Hurtado, Facultad de Economía y Negocios. 


\section{Introduction}

Supply chain management (SCM) is an area of increasing importance among enterprises and of growing academic interest (Mentzer and Gundlach, 2010). It is based on the concept of firms as part of multiple organizations oriented to the provision of goods and services for the final customer (Lambert and Cooper, 2000).

From this perspective, several studies have verified that integration and collaboration in the supply chain can provide important benefits to the companies involved. Among these benefits are added value, the creation of efficiencies and client satisfaction (Stock, Boyer and Harmon, 2010; Chow et al, 2008), which are represented by the reduction in inventories, improvements in service delivery and quality and shorter product development cycles (Corbett, Blackburn and Wassenhove, 1999).

Likewise, several studies have discussed the dynamic of SCM in small to medium-sized enterprises (SMEs) (Quayle, 2003; Arend and Wisner, 2005; Bhutta, Rana and Asad, 2007; Towers and Burnes, 2008; Bordonaba-Juste and Cambra-Fierro, 2009; Welker, Van der Vaart and Van Donk, 2008; Bayraktar et al, 20 I0; Li et al, 2009). The benefits of SCM for SMEs are evident from previous studies, among them obtaining a competitive advantage through relationships between clients and suppliers (Bordonaba-Juste and Cambra-Fierro, 2009) and the positive impact on performance (Bhutta, Rana and Asad, 2007).

Recent studies also highlight the contribution of SCM practices for innovations in SMEs (Zeng, Xie and Tam, 2010; Bos-Browers, 2010; Wang and Kafouros, 2009; Abereijo et al., 2009; Kaminski, Oliveira and Lopes, 2008; Kaufmann and Tödtling, 2002).

In general, SCM practices contributes to innovation in businesses through coordination and integration of tasks and activities throughout the chain (including clients, suppliers and the focal company) to facilitate the design, development and delivery of solutions (Srivastava, Shervani and Fahey, 1999). Innovation is understood as significant changes in products and processes (Bunnell and Coe, 200I), as well as the introduction of new products, processes and/or services in the market (OECD, 2005). SCM practices are understood as practices of collaboration and IT integration of SMEs with their clients and suppliers (Koh et al., 2007; Kim, 2009). Collaborative practices include activities developed jointly with suppliers and clients, based on customizing products or identifying and evaluating trends, for mass-production products, and considering improvements in production processes, the use of new materials and the incorporation of software (Kaminski, Oliveira and Lopes, 2008). The IT inte- gration is a SCM function that are carried out both internally and among enterprises by the members of the chain, and includes the application of basic internet services, as well as the use of business management systems and e-commerce (Redoli et al, 2008; Bayraktar et al, 2009).

It is particularly relevant to observe that despite the increased number of studies on SCM in SMEs, research on this practice associated with innovation are still incipient, in particular in developing countries (Wang and Kafouros, 2009). Given this, the aim of this study is to respond to the following research question: What is the impact of SCM practices on innovation in SMEs? To address this question, the SCM practices, which include collaborative practices and IT integration among SMEs are explored, as well as its contribution to innovation in these firms. The objective is to identify the contribution of SCM practices that are developed between the SMEs and their clients and suppliers for the innovation of products and processes in SMEs. The study attempts to capture the asymmetric small supplier-large client relationship in order to discuss the role of SCM practices as a support to innovation in SMEs. The fundamental argument is based on the fact that vertical cooperation with clients and suppliers plays an important role in processes of innovation among SMEs (Zeng, Xie and Tam, 20I0; Kaminski, Oliveira and Lopes, 2008).

The study has several major contributions. First, this is one of the few studies that incorporate the relationship with suppliers in the discussion about SCM in SMEs considering a context of dependence of large clients. Traditionally, studies about SCM in SMEs have focused on suppliers of large clients and have highlighted the positive and negative aspects of these relationships. Examples are the studies of Kauremaa, Kärkkäinen and Ala-Risku (2009), Huin, Luong and Abhary (2002), Arend and Wisner (2005), Chung and Kim (2003), Kaminski, Oliveira and Lopes (2008), Bordonaba-Juste and Cambra-Fierro (2009). This study complements the previous works in two ways. Firstly, the current study reinforces the perspective of large clients as the dominant part of the chain, and considers the extension of the relationship of SMEs with their suppliers in this context. As noted previously by Bigliardi, Colacino and Dormio (20I I), the client dependency is one of the main constraints to innovation of manufacturing SMEs. Secondly, the present research contributes to the previous studies by incorporating innovation as the result of SCM practices developed by SMEs with their clients and suppliers. Thirdly, based on SMEs as the focal companies in the study and assuming their relationship of dependence on a chain led by large clients, this study extends previous works to reflect this dependence on the relationship of SMEs with their suppliers. From this perspective, the impact of the interactions of both types of agents (clients and suppliers) on innovations in SMEs is verified. 
The article proceeds in the following manner. The next section, presents the model and the context of the study. Following that, the theoretical framework and the hypotheses of the research are presented, followed by the methodology used. Subsequently, the analysis and discussion of the results are presented, followed by the conclusions, managerial implications, limitations and future research directions.

\section{Model}

The framework developed in this study is shown in Figure $I$ and proposes that SCM practices influence innovation in products and processes.

The broad construct of SCM practices is represented in the model by two dimensions, collaborative practices and IT integration. The latter are represented by the adoption of both intra- and inter-organizational IT. In relation to adopting IT, it is important to note that the intra-organizational context includes the use of IT within the company in the production process, inventories management, design of prototypes and in other key functions for integration into the supply chain. Inter-organizational IT implies the transference of information among enterprises (Pagell, 2004; Bayraktar et $\mathrm{al}, 2010)$. The relationships established in the model occur in the context of SMEs.

\section{Theoretical Framework and Study Hypotheses}

\section{I SCM Practices and their Relationship to Innova- tion in SMEs}

Considered as a way to obtain the benefits of vertical integration without falling afoul of the formal costs of property (Arend and Wisner, 2005), SCM creates value for SMEs and permits the development of important competitive advantages by means of the relationships between suppliers and clients (Bordonaba-Juste and Cambra-Fierro, 2009). Among the benefits of SCM practices for SMEs are the positive impact on their operational and general performance (Bayraktar et al, 2009; Bhutta, Rana and Asad, 2007), providing competitive advantages through the relationship with clients and suppliers (Bordonaba-Juste and Cambra-Fierro, 2009) and support to innovative processes (Zeng, Xie and Tam, 2010; Doloreux, 2004; Kaminski, Oliveira and Lopes, 2008; Wang and Kafouros, 2009).

With respect to innovation, studies of different contexts show the contributions of collaboration between suppliers and clients for innovation in SMEs. For example, Kaminski, Oliveira and Lopes (2008) described the process of innovation in products by means of collaboration among SME suppliers and large clients in the mechanical sector in Brazil. Chung and Kim (2003) showed that collaborative practices in the supply chain facilitate innovation in products among Korean SMEs. Drayse (20II) emphasized the importance of the use of technologies shared with suppliers for innovation among small and large Canadian enterprises. Doloreux (2004) studied Canadian SMEs and found that innovation

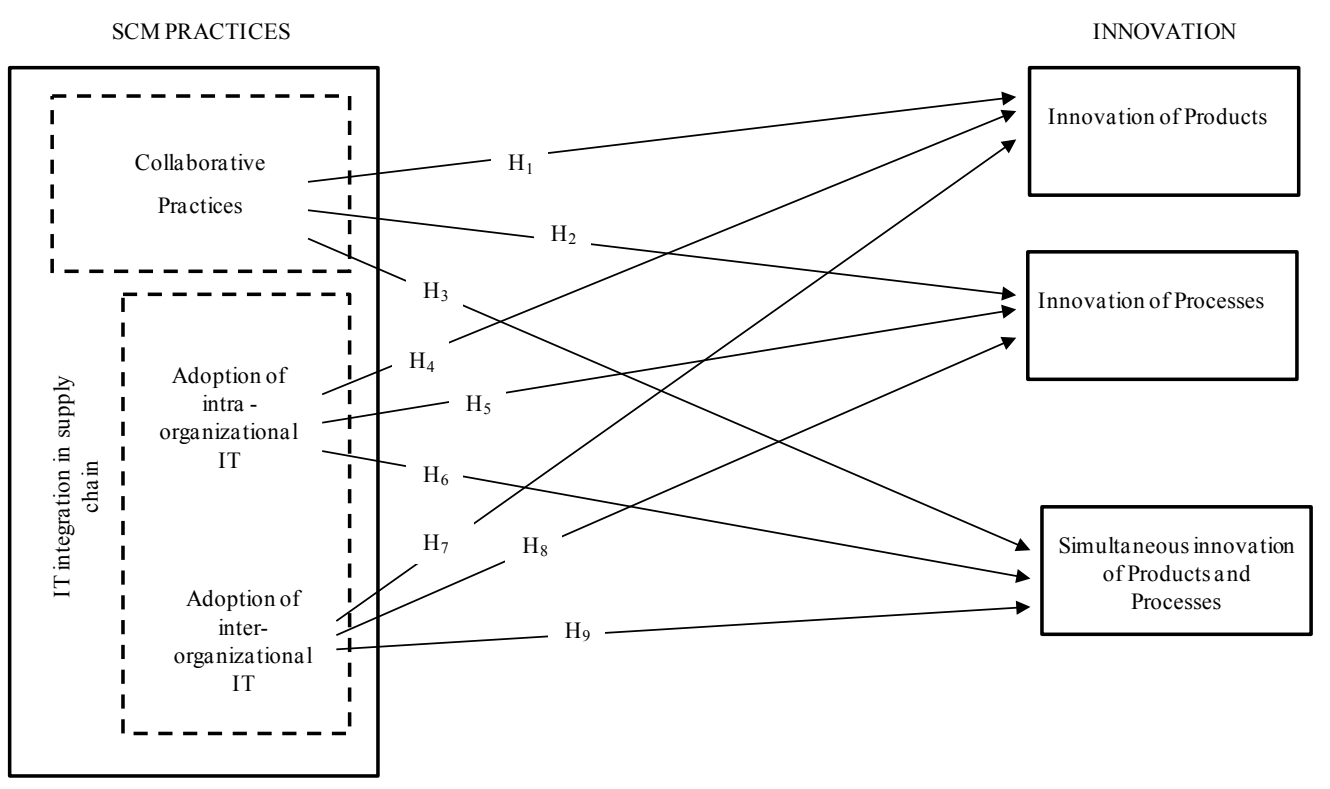

Figure I.Test Model of the Research

ISSN: 07I 8-2724. (http://www.jotmi.org)

Journal of Technology Management \& Innovation (C) Universidad Alberto Hurtado, Facultad de Economía y Negocios. 
in these enterprises is centered on external networks established with their suppliers and clients. Verhees and Meulenberg (2004) highlighted the importance of the closeness with clients for innovation in products among SMEs in Holland. Also in the context of Holland, Bos-Browers (2010) stressed that SMEs preferentially collaborate with clients for innovation in products or processes. In Spain, BordonabaJuste and Cambra-Fierro (2009) showed the importance of collaboration between SMEs and their suppliers for technological innovation. In this same context, Rochina-Barrachina, Mañez and Sanchis-Llopis (2010) noted that innovation in SMEs occurs essentially in productive processes. Likewise, Kaufmann and Tödtling (2002) demonstrated that SMEs in Austria develop few external relationships in innovative processes and that the exception is collaborations established predominantly with their clients. Zeng, Xie and Tam (2010) noted the collaboration of Japanese SMEs with their clients and suppliers predominantly in innovation. Similarly,Abereijo et al (2009) verified that clients and suppliers are the most important sources of technological innovations in Nigerian firms. In studying Italian firms, Bigliardi, Colacino and Dormio (20I I, p.90) demonstrated that "innovations have been mainly obtained through know-how of users and suppliers". Considering these collaborative processes in the context of the supply chain, Srivastava, Shervani and Fahey (1999) stressed that the contribution of SCM for innovation is coordination and integration of tasks among agents, allowing the exchange of ideas and knowledge for the design, development and delivery of solutions, considering that partnership among agents promotes the development of new types of materials, components and inputs.

Koh et al (2007) provide an extensive review of the literature that considers SCM practices. In the context of SMEs, we can note: close partnership with suppliers and clients; timely supply; e-procurement; information interchange with supplier through IT; and the integration of data in the production process. Such practices are associated with two dimensions of the overall construct of SCM practices, namely collaboration and integration (Kim, 2009). In the integration dimension, the use of IT prevails in intra- and inter-organizational processes (Kauremaa, Kärkkäinen and Ala-Risku, 2009; Bayraktar et al, 2009; Pagell, 2004), because of which from here on we will consider the adoption of intra- and inter-organizational IT in relation to IT integration the supply chain. The following sections discuss the role of each dimension in the innovation of products and processes in SMEs and present the hypotheses of the study. Notably, the text discusses innovation in both products and processes simultaneously as in the studies of Whitley (2002), Redoli et al (2008), Rennings and Rammer (20II), Drayse (20I I), and Bos-Brouwers (2010). However, assuming that SMEs can present one or other type of innovation or both at the same time, the approach of the hypotheses incorporates these specificities.

\section{I.I Collaborative practices in the supply chain and their role in innovation among SMEs}

SCM facilitates innovation in products through collaborative integration of processes among agents. In this context, the findings of Kaminski, Oliveira and Lopes (2008), studying the relationship between SMEs and large clients in the Brazilian mechanical-metals sector, showed that the innovation is driven by the development team of large companies, which interact with SME suppliers using their expertise as a databank for solutions in new projects. This information is available for all the agents in the chain and is constantly updated by new joint developments with suppliers (Kaminski, Oliveira and Lopes, 2008).

In the supplier-side, SMEs involved SMEs involved in collaborative processes with suppliers obtain knowledge from them about new technologies, markets and improved process, which leads to innovations in products and processes (Whitley, 2002).To emphasize the importance of the supplier in product development, Hartley, Zirger and Kamath (1997, p.58) stated "supplier management is an important, but often undervalued, product development activity". According to the authors, when SMEs work with technically competent suppliers it is possible to accelerate product development by avoiding problems. In doing so, the use of a cross-functional development team within the supplier's organization can help SMEs accelerate product development (Hartley, Zirger and Kamath, 1997). In studying supplier integration into new product development in large firms, Petersen, Handfield and Ragatz (2005, p.383) noted that a major reason for integrating suppliers into this initiative is "to access more and/or better information earlier in the development process by leveraging the supplier's expertise". One important aspect to consider in this integration is carefully selecting the supplier, which will promote the development of a better design of products, and probably a better financial performance (Petersen, Handfield and Ragatz, 2005).

The finding of Chung and Kim (2003), studying suppliers in the automotive and electronics industries in Korea, showed that vertical collaboration, in a SCM perspective, facilitates innovation in products by means of integration with suppliers. In this case, the supplier companies are medium-sized and large and innovation emerges from the combination of technical know-how between suppliers and clients and the supplanting of the weaknesses of suppliers by means of common objectives, which imply coordinating information flows and production times in conjunction with suppliers and/or clients (Drayse, 20II) and allowing synchronization of operations (Bordonaba-Juste and Cambra-Fierro, 2009), which facilitates innovation in SMEs (Chung and Kim, 2003). 
Resuming the theoretical discussion presented above, it is assumed that collaborative practices in the supply chain contribute to innovation in products and processes, which is generated by the combination of technical know-how between suppliers and clients (Whitley, 2002). As Theinsathid, Chandrachai and Keeratipibul (2009) verified in their study, many of the factors that drive innovation are derived in collaboration with technology push and demand pull. Based on these discussions and considering that collaboration among the agents provides a set of SCM practices (Bayraktar et al, 2009; Bayraktar et al, 2010; Kim, 2006; Bhutta, Rana and Asad, 2007), the following hypotheses are presented:

$\mathrm{HI}$ : Collaborative practices in the supply chain positively influence innovation of products in SMEs.

$\mathrm{H}$ 2: Collaborative practices in the supply chain positively influence innovation of processes in SMEs.

Following the previous discussions and assuming that enterprises can present innovations simultaneously in products and processes (Drayse, 20I I; Rennings and Rammer, 20I I; Bos-Brouwers, 2010), it is also proposed that:

$\mathrm{H} 3$ : Collaborative practices in the supply chain positively influence innovation simultaneously in products and processes among SMEs.

\section{I.2 IT integration in the supply chain and their role in innovation among SMEs}

The central challenge of the SCM practices is the integration of the firms with clients and suppliers. In the integration with suppliers, firms see them as an option to reduce costs by means of cooperative work (Gunasekaran, Patel and McGaughey, 2004). On the other hand, service to the client is the most important attribute for success in the supply chain (Coyle, Bardi and Langley, 2003). Clients are considered part of this success when they interact with the firm in the development of products and processes according to their needs. The use of IT in SCM is the basic condition to ensure interaction among enterprises and their suppliers and clients (Bayraktar et al, 2009). The central argument is that for the coordinated development of activities throughout the supply chain it is fundamental to ensure the flow of information within and among the departments and enterprises involved, which is supported by information systems (IS) (Bayraktar et al, 2009; Kauremaa, Kärkkäinen and Ala-Risku, 2009).

The development of IS in SMEs follows two main orientations: the customer dominance dimension and the strategic focus. The strategic focus "reflect the two main objectives of adopting IS/IT: cost reduction and added value" (Levy, Powell and Yetton, 2002, p.342), and complement the business conditions that contribute to and influence the adoption of mechanisms for the exchange of information in the supply chain (Welker, Van der Vaart and Van Donk, 2008). The customer dominance reflects dependence on clients. This is typical when the SME is a first line supplier of large clients, which in general means that the SME has only a few clients that exercise a lot of power (Levy, Powell and Yetton, 2002). Among the requirements of this relationship is the use of inter-organizational systems to communicate with clients, which increase as the relationship intensifies (Boeck, Bendavid and Lefebvre, 2009). From this perspective, the need to integrate logistical activities throughout the chain leads large enterprises to exercise strong pressure on SME suppliers to adopt compatible management practices (De Toni, Nassimbeni and Tonchia, 1995). If, on the one hand, SMEs gain some advantages by involving themselves in integration with large clients, it is also evident that there are some disadvantages, such as the risk of quasi-integration, unilateral dependence and conflicts of the non-distribution of the original gains of the partnership (Gélinas and Bigras, 2004).

In a study of SMEs in northern Europe, Kauremaa, Kärkkäinen and Ala-Risku (2009) found two approaches to operating information systems in SMEs, one in which integration is completely automated and another that involves people in some part of data interchange. In the first case, the systems substitute for conventional methods of communication and evolve toward the integration of databases of clients and their suppliers. In the second case, the data of the internal information system of a company are electronically provided to another company, which processes the information manually. This proposal involves the use of Internet and web sites (Kauremaa, Kärkkäinen and Ala-Risku, 2009). According to the authors, both systems bring benefits to SMEs, although automated integration systems provide greater benefits.

In general, the literature reveals difficulties on the part of SMEs in adopting IT, and IS. Among the main inhibiting factors is the scarcity of resources to adopt solutions of IS that would permit efficient SCMs. These systems are expensive and demand sophisticated internal systems, while SMEs do not have the necessary resources for their implementation (Stefansson, 2002; Eagan, Clancy and O'Toole, 2003; Bayraktar et al, 2009). As Stefansson (2002) stated, smaller companies often do not have resources to implement information technologies, with the consequence that they risk being permanently excluded from integrating their operations into the supply chain. Furthermore, the cost of accessing these technologies, the perceived need for the technology, poor technology skills and management's lack of commitment are other reasons that information technologies are not adopted by the SMEs (Eagan, Clancy and O'Toole, 2003). Moreover, SMEs have difficulties in raising finance to invest in information technologies (Damaskopoulos and Evgeniou, 
2003) and do not have sufficient financial resources to employ consultants to help them in implementing these technologies (Soriano et al., 2002).

The result can be the loss of competitiveness by SMEs (Kauremaa, Kärkkäinen and Ala-Risku, 2009). Large enterprises use electronic data interchange technology (EDI), but experience problems in communicating with small companies because the latter often lack basic information technology, which can exclude them from integrated logistical operations in the supply chain (Stefansson, 2002).

In this sense, the adoption of IT and the use of information systems is an essential condition for advancing the relationships of SMEs with their clients and/or suppliers to more collaborative stages (Boeck, Bendavid and Lefebvre, 2009). In the majority of cases, and particularly when dealing with large clients, it is they that lead the process of adopting interorganizational information systems (Kauremaa, Kärkkäinen and Ala-Risku, 2009). Essentially, by sharing information with their suppliers, large companies seek operational efficiency and expect to work cooperatively to provide better services, products and innovative technologies (Gunasekaran, Patel and McGaughey, 2004).

In general, relations in the supply chain provide mechanisms through which the closeness of agents creates opportunities to improve the competitiveness of those involved that can be extended geographically through information and communication technologies (ICTs) (Macpherson, Jones and Zhang, 2005), which may facilitate higher levels of collaboration among geographically dispersed work groups (Kabanda, 2008). As Macpherson, Jones and Zhang (2005) observed, these opportunities generate capacities for innovation among the enterprises involved. From this perspective, innovation in products and processes is facilitated by the flow of knowledge established between public research institutions and firms, as well as among firms (Redoli et al, 2008). Considering this flow of knowledge in the context of SCM, "the interactions and interdependencies between organizations (including contractors, government, clients, designers, sub-contractors and suppliers) clearly have an important role in shaping the process of production and innovation" (Dewick and Miozzo, 2004, p.330). A major part of these interactions occur through the exchange of information that is facilitated by the use of IT and supposes intensive collaboration between SMEs and external agents (Kaufmann and Tödtling, 2002).

With regard to the process of innovation in SCM, the findings of Kaminski, Oliveira and Lopes (2008) indicate that the development of new products among SMEs occurs through the exchange of information and the integration of processes with their clients (Kaminski, Oliveira and Lopes, 2008).
Taking into account that the integration of SMEs with their clients and suppliers occurs in great measure through the use of IT (Kauremaa, Kärkkäinen and Ala-Risku, 2009) and that IT have an important role in the innovation of products and processes among SMEs (Redoli et al, 2008; Macpherson, Jones and Zhang, 2005; Kaminski, Oliveira and Lopes, 2008), the following hypotheses are proposed:

H4: Practices of integration in the supply chain through the use of inter-organizational IT positively influence innovation in products among SMEs.

H5: Practices of integration in the supply chain through the use of inter-organizational IT positively influence innovation in processes among SMEs.

H6: Practices of integration in the supply chain through the use of inter-organizational IT positively influence innovation simultaneously in products and processes among SMEs.

In the internal context of companies, the use of real time communication methods influences the integration of key functions of the supply chain, that is, operations, purchasing and logistics (Pagell, 2004). The integration of internal functions is the initial condition for the exchange of information with partners, which evolve toward innovation associated with improvement or renewal of business processes (Levy, Powell and Yetton, 2002).

The management of internal functions of the supply chain includes various activities from planning and the control of production, the supply of inputs for production and the logistics and optimization of the distribution network.All these activities demand an information flow within and among departments and enterprises, which are supported by information systems that include the use of IT in practices, such as material requirements planning (MRP) and enterprise resource planning (ERP) (Bayraktar et al, 2009). Underlying the use of these systems is internet as the base of the corporate networks of SMEs (Redoli et al, 2008).

The use of information technologies in the internal context of SMEs is considered one of the key factors in innovation (Redoli et al, 2008). According to Redoli et al (2008), the introduction of new or improved products or processes (in-house innovation) demands the use of information technologies that become supports to these activities. For example, IT is associated with the use of new manufacturing technologies, as in the case of computer-driven machines, that can lead innovation in products and processes among enterprises (Drayse, 20II).

In general, these innovative processes develop informally in SMEs, whose strategy is based on incremental innovations 
and "innovations in processes that involve the introduction of new machinery" (Rochina-Barrachina, Mañez and SanchisLlopis, 2010, p. 164). Among the informal inputs for innovation are technical information, efforts to assimilate imported technologies and the design of products (Rochina-Barrachina, Mañez and Sanchis-Llopis, 2010). These are developed internally and suppose the use of information technologies. Considering that activities for integration into the supply chain internal to enterprises consist of the use of IT for the exchange of information among sectors of the enterprise, the use of IT in productive processes, in inventory management and in the design of prototypes (Bayraktar et al, 2009; Koh et al, 2007; Pagell, 2004), and taking into account the previous discussions, it is supposed that:

H7: IT integration in the supply chain through the adoption of intra-organizational IT positively influences innovation in products among SMEs.

H8: IT integration in the supply chain through the adoption of intra-organizational IT positively influences innovation in processes among SMEs.

H9: IT integration in the supply chain through intra-organizational IT positively influences innovation simultaneously in products and processes among SMEs.

\section{Methodology}

\section{I Sampling and Data Collection}

The data used in this study were drawn from the database of the project 'Demography of the Regional SMEs", carried out by researchers from the Entrepreneurship and the SME Center (CEMP) of the Universidad Católica del Norte, Chile. The current database covers a representative sample of 653 SMEs in the Antofagasta Region, northern Chile, and includes firms that are suppliers of the mining industry and others that are not. The data for the project were gathered between November 2007 and April 2008 by means of a cross-sectional survey. The questionnaires were applied through personal interviews and the respondents were owners of SMEs.

The criterion adopted for the definition of SME was the volume of sales of each enterprise. This is the criterion adopted by the Chilean Government, considering that a SME has an annual sales volume of not less than EUR 79,303.7I and not greater than EUR 3,304,321.25 (these values are in Chilean pesos, national currency, converted to Euros at the February 24,20 II exchange rate).

Taking into account that the objective of this work is to study SMEs, considering their link to large companies in the mining sector, the research covered a total of 318 SMEs that meet this criterion. Of these, 200 are small companies with annual sales between EUR 79,303.7I and EUR 826,080.00, and 118 are medium-sized companies with annual sales between EUR 826,081.00 and EUR 3,304,321.25, in accordance with the criteria of SME size presented in the previous paragraph. Some $46.9 \%$ of the population belongs to the service sector, as can be observed in Graph I.

The data shown in Graph I indicate that services are protagonists in the relationships of SMEs that are, in large part, characterized by their dependence on clients. As can be observed in Graph 2, more than half the SMEs concentrate between $21 \%$ and $60 \%$ of their sales with just one client. This situation reflects the importance for SMEs of adjusting to the requirements of their clients and of implementing practices that improve their operative performance (Bayraktar et al, 2010), given that they are subject to frequent changes in demand and have difficulties to balance the supply chain (Towers and Burnes, 2008).

\subsection{Research Variables and Measurement}

Based on the literature review, a set of variables was defined that represent the overall construct of SCM practices, including collaborative practices and IT integration (the adop-

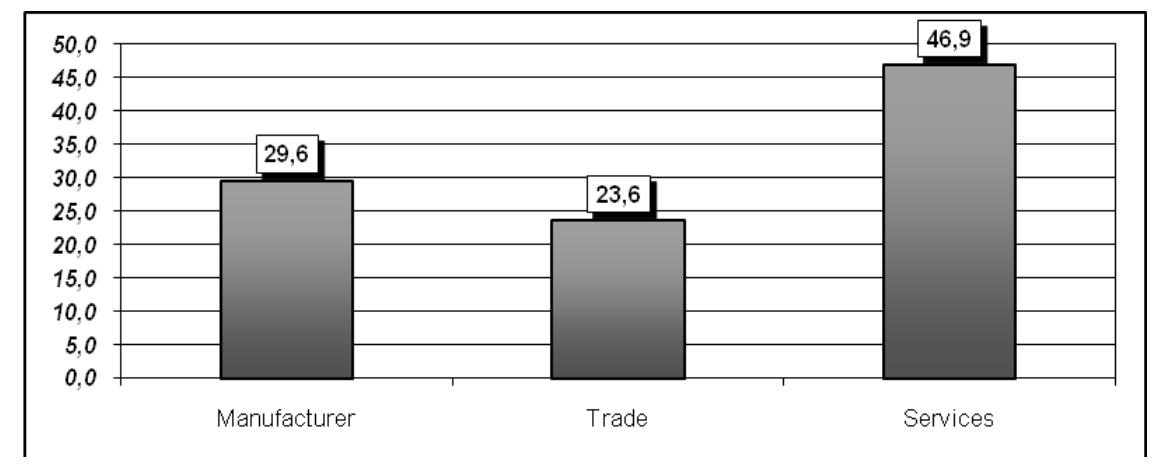

Graph I. Distribution of the sample of SMEs according to the area of activity

ISSN: 07 I8-2724. (http://www.jotmi.org)

Journal of Technology Management \& Innovation @ Universidad Alberto Hurtado, Facultad de Economía y Negocios. 


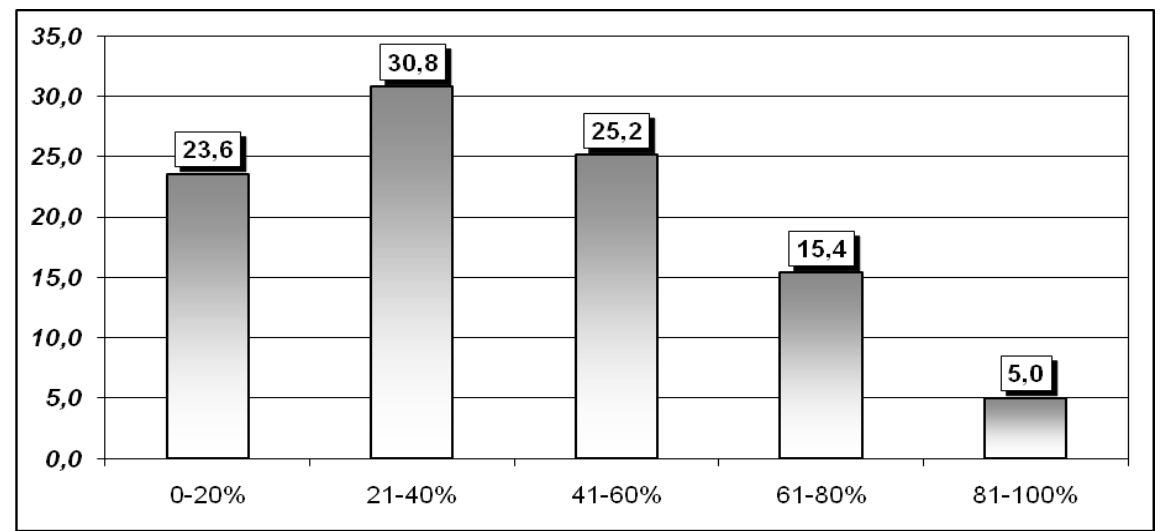

Graph 2. Concentration of sales of SMEs in only one client

\begin{tabular}{|c|c|c|}
\hline Dimension & Measurement item & Source \\
\hline $\begin{array}{l}\text { Collaborative } \\
\text { practices in the } \\
\text { supply chain }\end{array}$ & $\begin{array}{l}\text { Contracts of more than one year } \\
\text { Client as source of ideas for innovation } \\
\text { Supplier as source of ideas for innovation } \\
\text { E-procurement practices }\end{array}$ & $\begin{array}{c}\text { Bayraktar et al (2009), Bayraktar et } \\
\text { al (2010), Koh et al. (2007). }\end{array}$ \\
\hline $\begin{array}{l}\text { IT integration } \\
\text { (adoption of IT } \\
\text { inter-organiza- } \\
\text { tional) }\end{array}$ & $\begin{array}{l}\text { Use of IT to communicate with clients and sup- } \\
\text { pliers } \\
\text { Use of IT for the sale of goods and services to } \\
\text { clients } \\
\text { Use of IT for post-sale services }\end{array}$ & $\begin{array}{c}\text { Kauremaa, Kärkkäinen and Ala-Risku } \\
\text { (2009); Bayraktar et al (2009) }\end{array}$ \\
\hline $\begin{array}{l}\text { IT integration } \\
\text { (adoption of IT } \\
\text { intra-organiza- } \\
\quad \text { tional) }\end{array}$ & $\begin{array}{l}\text { Use of IT for production } \\
\text { Use of IT to exchange information among sectors } \\
\text { of the enterprise } \\
\text { Use of IT to administer inventories } \\
\text { Use of IT to design prototypes }\end{array}$ & $\begin{array}{l}\text { Bayraktar et al (2010); Koh et al } \\
\text { (2007); Pagell (2004). }\end{array}$ \\
\hline Innovation & $\begin{array}{l}\text { Development of new products for the market } \\
\text { Adaptations of existing products } \\
\text { Development of new processes for the market } \\
\text { Adaptations of existing processes }\end{array}$ & OECD (2005) \\
\hline
\end{tabular}

Table I. Research variables and measurement 
tion of intra- and inter-organizational IT). These variables are associated with the dimensions referred to in the proposed model (see Figure I) and that it is supposed provide support to innovation in SMEs. Table I shows the variables used in the model, as well as indicating the dimensions of innovation that were considered as dependent variables.

In relation to collaborative practices in the supply chain including clients and suppliers: a) the variables 'long-term contracts (of more than one year)' and 'client as source of ideas for innovation" were considered as a proxy of close partnership with clients; b) the variables 'supplier as source of ideas for innovations" and "practices of e-procurement' represents close partnership with suppliers. Both (close partnership with clients and suppliers) represent an effort to collaborate strategically in the chain (Bayraktar et al, 2010). The variables of IT adoption are inserted in the context of SCM in that they reveal the effort of SMEs to accompany the flow of information associated with producing products and/or services, both internally and externally (Mentzer et al, 200I). As Redoli et al (2008) noted, the use of these technologies is supported by internet, which implies that access to internet, the use of basic internet services, as well as the use of business management systems and e-commerce, should be considered in studying information technologies in SMEs, which also justifies the identified variables. These variables represent IT integration in the supply chain considering their role as facilitators of SCM, according to Bayraktar et al (20I0) and Welker,Van der Vaart and Van Donk (2008). With the exception of innovation variables, all the other variables were measured on the Likert scale of seven points. Respondents were asked to indicate the level of adoption of collaborative practices and IT integration in the supply chain, at one extreme ' $\mathrm{l}$ ' being considered 'extremely low level of adoption' and at the other, ' 7 ' being considered 'extremely high level of adoption'.

The term IT was defined for survey subjects as the use of internet for the exchange of information with clients and suppliers, the use of management systems such as e-procurement, and the use of information associated with production processes and for the internal exchange of information following what was considered by Redoli et al (2008), Li et al (2009) and Hafeez et al (2010). The respondents could mark any point on the scale.

In relation to innovation, the four variables identified in Table I were measured with categorical questions. The surveyors marked the option "yes" or "no" for innovation in products and/or processes in the last three years, i.e. from 2004 to 2006. Chung and Kim (2003) also considered a period of three years to identify innovations in SMEs in function of their relationships in the supply chain. The four variables were grouped into two for the purpose of analyzing the data. One reference is innovation in products, considering both the development of new products for the market and adaptations to existing products. The other reference is innovations in processes and this also includes both the development of new processes and the adaptation of existing processes. The criterion to group the variables was based on the definition of innovation of the Organization for Economic Co-operation and Development (OECD), of which Chile is a member. According to the OECD (2005, p.58), product innovation "consists of the introduction of a new, or significantly improved, good or service in terms of its characteristics or in terms of the use to which it is applied". Process innovation "is the introduction of a new or significantly improved process of production or distribution".

According to the data, $75.2 \%$ of the investigated SMEs revealed innovations. Of these, $59.4 \%$ innovate simultaneously in products and processes; $10.7 \%$ innovate solely in products; and $5.1 \%$ innovate solely in processes. Also, $24.8 \%$ of the firms revealed that they had not innovated during the period that was analyzed.

\subsection{Data Analysis}

Before proceed the analysis of the data, the reliability of the construct also was examined to ensure the items collectively measured their intended construct consistently (Churchill, 1979). Internal consistency reliability was examined in the way of Cronbach's alpha. The results revealed adequate reliability indexes (Table 2).

The data were analyzed by multinomial logistic regression. This technique was chosen according to the objective of this study and it is an appropriate technique when the dependent variable is nominal polytomic and the independent variables are metric (Hair et al, 1999). The normality of the data was verified by means of the results of skewness and kurtosis, which revealed indices corresponding to a normal distribution according Hair et al (1999), with limits between +3 and -3 (kurtosis) and between $+I$ and $-I$ (skewness). The results of the Pearson correlation for the independent variables did not show problems of multicollinearity once the highest was 0,64 , which did not represent a problem for subsequent analysis that imply a relationship of dependence (Lin and Chen, 2005). These results reveal that the data are adequate for the analysis, without violating the suppositions of the model, according to what was indicated by Hair et al (1999). The dimensions of SCM practices, namely collaborative practices and IT integration in the supply chain (adoption of intra- and inter-organizational IT) were analyzed by means of their respective variables (referred to in Table I), which are the independent variables of the model (See Figure I). Rajesh et al (20II) use a similar approach to carry out multiple linear regressions with independent variables 


\begin{tabular}{clcc}
\hline Construct & \multicolumn{1}{c}{ Dimensions of Construct } & $\begin{array}{c}\text { Cron- } \\
\text { bach's } \\
\text { alpha for } \\
\text { dimensions } \\
\text { SCM }\end{array}$ & $\begin{array}{c}\text { Cronbach's alpha } \\
\text { for overall con- } \\
\text { struct }\end{array}$ \\
$\begin{array}{c}\text { Collaborative practices } \\
\text { Practices }\end{array}$ & $\begin{array}{l}\text { IT integration (adoption of inter-organiza- } \\
\text { tional IT) }\end{array}$ & 0.704 & \\
& $\begin{array}{l}\text { IT integration (adoption of intra-organiza- } \\
\text { tional IT) }\end{array}$ & 0.741 & 0.803 \\
$\begin{array}{c}\text { Innova- } \\
\text { tion }\end{array}$ & \begin{tabular}{l} 
Innovation \\
\hline
\end{tabular} & 0.809 & 0.809 \\
\hline
\end{tabular}

Table 2. Results for the reliability of the constructs

representative of functional dimensions, value chain and strategic capabilities of the third-party logistics (3PL) providers.

In terms of innovation, four groups of SMEs were defined: the group that has innovated simultaneously in products and processes; 2 ) the group that presents innovation only in products; 3 ) the group that has innovated only in processes; y 4) the group of companies that do not present innovations in the period considered. These were the dependent variables in the multinomial logistic regression model, with the variable "no innovation" being considered the reference category in the analysis.

\section{Results}

In relation to the multinomial regression model, the results presented in Table 3 shows a -2 log likelihood of 527,182 (AIC $=612,643$, pseudo $R 2=0.286)$ and the significance of $99 \%$ ( $p$ value $=0.000)$, which indicates that the model is adjusted to the statistical parameters.

As can be observed in Table 3, the support of the overall construct of SCM practices changes in function of the type of innovation. In terms of the dimensions of the construct, i.e. collaboration and IT integration, collaborative practices, such as 'clients as source of ideas for innovation' that represent close partnership with clients, positively influence innovation simultaneously in products and processes and also in products alone. In terms of IT integration in the supply chain, there are positive and/or negative associations of different variables with the innovation.

In the following sections we discuss these results in function of the hypotheses of the study. It is important to note that the tests of hypotheses were based on two-sided test.

\section{I The Support of Collaborative Practices in the Supply Chain to the Innovation of SMEs}

Considering innovation in products $(\mathrm{HI})$, although the studied SMEs present collaborative practices with clients and suppliers, the results show that variable 'clients as source of ideas for innovation' is only practice that positively influences innovation in products among SMEs. The significance of $90 \%$ ( $p$ value $=0.059$ ) and a positive coefficient of 0.246 reveal that contact by SMEs with their clients is important for innovation in products. However, the other variable of collaboration with clients, namely 'contracts of more than one year' does not contribute to this type of innovation. The result is insignificant for this variable. Likewise, the collaborative practices of SMEs with their suppliers are not significant for innovation in products. For instance, the variable 'e-procurement practices' present a low coefficient $(0.015)$ and is not significant. The negative coefficient for 'supplier as source of ideas for innovation' suggests that this practice is unfavorable for innovation in products among SMEs. These results indicate that $\mathrm{HI}$ is partially accepted.

Similar results are evidenced in collaborative practices associated with innovation in processes $(\mathrm{H} 2)$ among SMEs. A positive association is seen in these enterprises between 'eprocurement practices' and innovation. Although the level of significance is relatively low ( $p$ value $=0.082$ ), the coefficient is 0.325 and positive, which could indicate an initial effort of SMEs to approach their suppliers through information flows and one driver for innovation. The other collaborative practice with suppliers, namely 'supplier as source of ideas for innovation', does not present effect in innovation in process which suggests that SMEs are not closer to suppliers through initiating innovations in process. Furthermore, it is worth noting that the SMEs do not benefit from close partnership with clients given that the results show that this variable is not significant for innovation in processes. The negative coefficients for 'contracts of more than one year'

ISSN: 07I8-2724. (http://www.jotmi.org)

Journal of Technology Management \& Innovation (c) Universidad Alberto Hurtado, Facultad de Economía y Negocios. 
Table 3. Results of the influence of SCM practices and IT adoption on innovation among SMEs

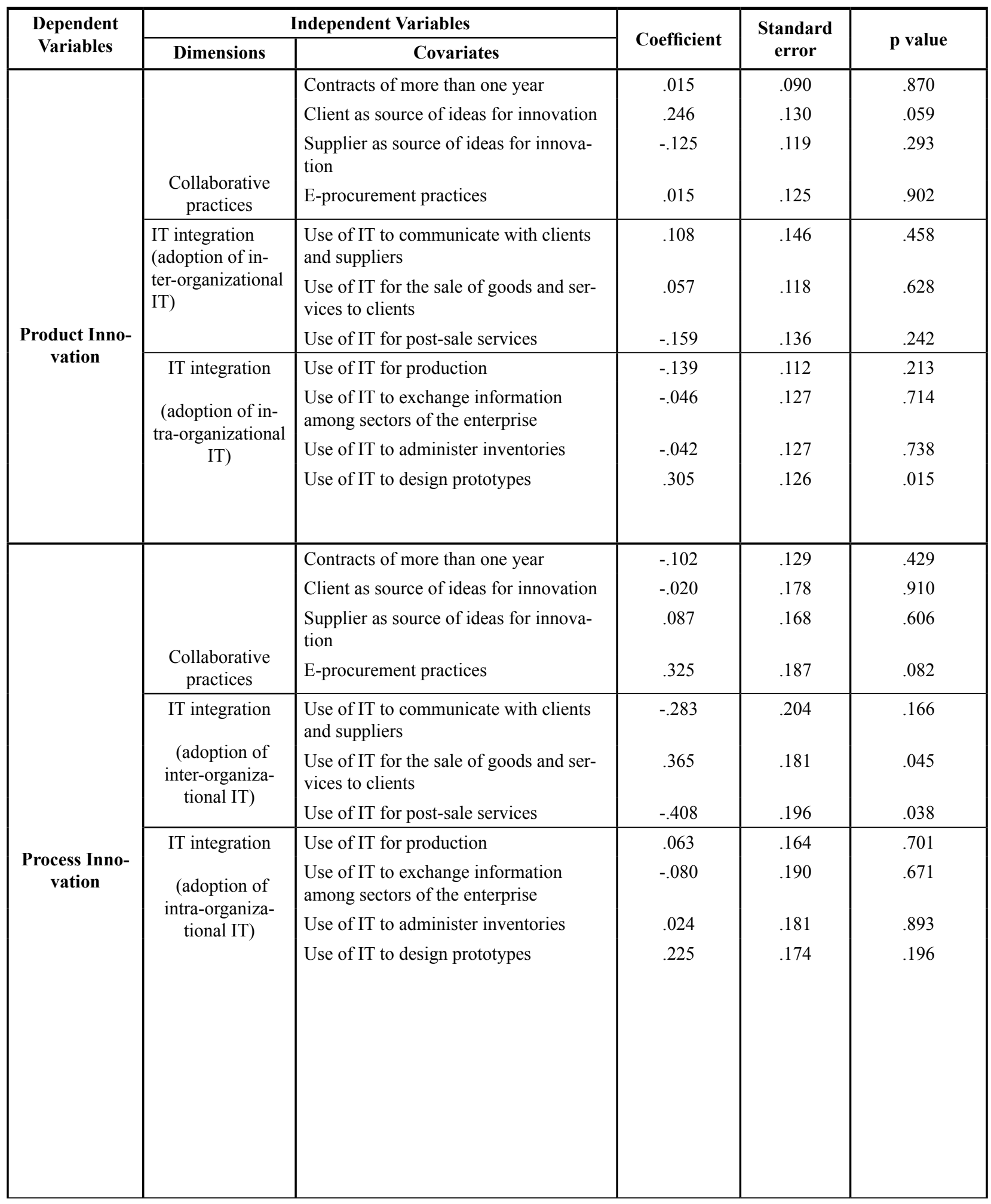




\begin{tabular}{|c|c|c|c|c|c|}
\hline \multirow{3}{*}{$\begin{array}{c}\text { Product and } \\
\text { Process Inno- } \\
\text { vation }\end{array}$} & $\begin{array}{c}\text { Collaborative } \\
\text { practices }\end{array}$ & $\begin{array}{l}\text { Contracts of more than one year } \\
\text { Client as source of ideas for innovation } \\
\text { Supplier as source of ideas for innova- } \\
\text { tion } \\
\text { E-procurement practices }\end{array}$ & $\begin{array}{l}.073 \\
.348 \\
-.051 \\
-.028\end{array}$ & $\begin{array}{l}.065 \\
.090 \\
.083 \\
.092\end{array}$ & $\begin{array}{r}.259 \\
.000 \\
.534 \\
.762\end{array}$ \\
\hline & $\begin{array}{l}\text { IT integration } \\
\text { (adoption of } \\
\text { inter-organiza- } \\
\quad \text { tional IT) }\end{array}$ & $\begin{array}{l}\text { Use of IT to communicate with clients } \\
\text { and suppliers } \\
\text { Use of IT for the sale of goods and ser- } \\
\text { vices to clients } \\
\text { Use of IT for post-sale services }\end{array}$ & $\begin{array}{l}-.190 \\
.064 \\
.104\end{array}$ & $\begin{array}{l}.102 \\
.086 \\
.093\end{array}$ & $\begin{array}{l}.061 \\
.456 \\
.268\end{array}$ \\
\hline & $\begin{array}{l}\text { IT integration } \\
\text { (adoption of } \\
\text { intra-organiza- } \\
\quad \text { tional IT) }\end{array}$ & $\begin{array}{l}\text { Use of IT for production } \\
\text { Use of IT to exchange information } \\
\text { among sectors of the enterprise } \\
\text { Use of IT to administer inventories } \\
\text { Use of IT to design prototypes }\end{array}$ & $\begin{array}{r}.174 \\
-.014 \\
-.108 \\
.256\end{array}$ & $\begin{array}{l}.083 \\
.096 \\
.094 \\
.087\end{array}$ & $\begin{array}{r}.037 \\
.883 \\
.253 \\
.003\end{array}$ \\
\hline $\begin{array}{l}\text { Reference categ } \\
\mathrm{N}=318 \\
2 \text { Log likelihoo } \\
\mathrm{AIC}=612,643\end{array}$ & $\begin{array}{l}\text { : No innovation } \\
527,182\end{array}$ & & & & \\
\hline
\end{tabular}

and 'client as source of ideas for innovation', although they are not significant, led to supposing a negative association between collaborative practices with clients and innovation in processes among SMEs. Based on the results presented, $\mathrm{H} 2$ is partially accepted.

Considering innovation simultaneously in products and processes $(\mathrm{H} 3)$, the contribution of collaborative relationships of SMEs with their clients is evident for innovation. The significance of $99 \%$ ( $p$-value $=0.000$ ) and a positive coefficient of 0.348 for 'client as source of ideas for innovation' confirm this relationship and indicates a strong relationship among the variables. However, this is the only collaborative practice that favors simultaneous innovation in products and processes among SMEs. As in the case of SMEs that innovate only in products $(\mathrm{HI})$ or only in processes $(\mathrm{H} 2)$, the variable 'contracts of more than one year' is not significant for innovation simultaneously in products and processes. Likewise, the variables indicate collaborative practices with suppliers are not associated with this type of innovation. These results led to partially accepting $\mathrm{H} 3$.

\subsection{The contribution of IT integration in supply chain to innovation among SMEs}

The results of the regression reveal that the adoption both intra- and inter-organizational IT favors innovation in products and processes in SMEs. However, there are some particulars of this association to be considered, in function of the adoption of intra- and inter-organizational IT.

With regard the adoption of inter-organizational IT, there is scarce evidence of its association with innovation in the studied SMEs, the relationship being negative in some cases. In terms of the influence of adopting inter-organizational IT on innovation in products $(\mathrm{H} 4)$, both IT integration practices of SMEs with their suppliers and those developed with their clients do not offer support to this type of innovation. The non-significance of the variables representative of these practices lead to rejecting $\mathrm{H} 4$. For the group of SMEs that innovate in process (H5), the 'use of IT for the sale of goods and services to clients' is positively associated with this type of innovation. The coefficient of 0.365 and the $p$ value $=0.045$ confirms this relationship. On the other hand, a negative relationship between IT inter-organizational and innovation in processes was evidenced in this group of SMEs in association with the 'use of IT for post-sale services' (co-

ISSN: 07 I8-2724. (http://www.jotmi.org) 
efficient $=-0.408$ and $p$ value $=0.038$ ). Thus, the greater the use of IT for post-sale services, the less the innovation in processes in SMEs. The variable 'use of IT to communicate with clients and suppliers' did not reveal an association with innovation in processes. These results lead to partially accepting $\mathrm{H} 5$. With regard SMEs that innovate simultaneously in products and processes $(\mathrm{H} 6)$, a weak and negative relation was found with the 'use of IT to communicate with clients and suppliers', this being the only variable to be related innovation. The coefficient of -0.190 and the $p$ value $=0.06 \mathrm{I}$ indicate that the greater the use of IT to communicate with clients and suppliers, the less innovation in products and processes. The other two variables that represent IT integration through the adoption of inter-organizational IT did not reveal influence of this type of innovation. The 'use of IT for the sale of goods and services to clients' and 'use of IT for post-sale services' are insignificant in the model. Based on these associations, $\mathrm{H} 6$ is rejected.

In relation to the internal context (intra-organizational), and considering innovation in products $(\mathrm{H} 7)$, the 'use of IT in the design of prototypes' is the only variable highlighted among the SMEs that innovate in this area. The level of significance of $99 \%$ ( $p$ value $=0.015$ ) and a positive coefficient of 0.305 for this variable indicates that the greater the use of IT for the design of prototypes, the greater the innovation in products in SMEs. The other variables, i.e. 'use of IT for production', 'use of IT to exchange information among sectors of the enterprise', and 'use of IT to administer inventories', did not reveal influence in innovation of products. These results reflect a weak relationship between the adoption of intraorganizational IT and innovation in products, which allows for a very partial acceptance of $\mathrm{H7}$. In terms of the relationship between the adoption of intra-organizational IT and innovation in processes $(\mathrm{H} 8)$, none of the variables considered in the analysis reveal the influence on this type of innovation, because of which $\mathrm{H} 8$ is rejected. On the other hand, the adoption of IT seems to favor innovation in SMEs that innovate simultaneously in products and processes (H9). In this case, the positive influence lies in the technologies used in the production (coefficient $=0.174$ and $p$ value $=0.037$ for 'use of IT for production') and in 'use of IT to design of prototypes' (coefficient $=0.256$ and $p$ value $=0.003$ ). For this last variable, the level of significance of $99 \%$ indicates a strong relationship with simultaneous innovation in products and processes. However, the results for 'the use of IT to administer inventories' and 'the use of IT to exchange information among sectors of the enterprise' indicate that these practices do not favor this type of innovation. These results lead to partially accepting $\mathrm{H}$.

\section{Discussion}

In relation to collaborative practices, the results reveal positive and significant associations with innovation by means of two of the four tested variables. The variables are 'clients as a source of ideas for innovation' and 'e-procurement practices'. In terms of the duration of the relationship with clients ('contracts of more than one year'), which also reflects close partnership with clients as does the variable 'clients as a source of ideas for innovation', the results reveal that this aspect does not influence innovation in any of the cases, whether innovation simultaneously in products and processes or innovation only in products or in processes. The same happens in the relationships established with suppliers ('suppliers as a source of ideas for innovation').

However, although not all the collaborative practices provide support to innovation, the results tend to reaffirm the findings of Bos-Browers (2010), Kaufmann and Tödtling (2002) and Kaminski, Oliveira and Lopes (2008), which indicate that SMEs essentially collaborate with their clients for innovation. In the studied context, the practice that is strongly related to innovation in products and is also simultaneously related to innovation in products and processes is "clients as a source of ideas for innovation', which supports this perspective. In terms of collaborative practices established with suppliers, there was an evident relationship between 'e-procurement practices' and innovation in processes. Although insipient in nature, this result is notable because of the participation of suppliers in the innovative processes of SMEs, as was evidenced in the studies of Bordonaba-Juste and Cambra-Fierro (2009) and Drayse (20I I). Collaboration with suppliers for innovation in processes among SMEs was also found by Rochina-Barrachina, Mañez and Sanchis-Llopis (2010). On the other hand, the relationship of this variable to innovation in products was not found, nor in simultaneous innovation in products and processes.

Also, the variable 'supplier as a source of ideas for innovation' was not related to either type of innovation. Possibly because of prioritizing their relationships with their clients, given that it is the latter that dominate the relationship (as evidenced in the concentration of sales with only one client as shown in Graph 2), the SMEs dispense with suppliers as integral agents in the supply chain, as reflected in some findings of this study.

In terms of IT integration, the results lead to the inference that there is a weak relationship between adopting IT interorganizational and innovation in SMEs that also reflects the insipience of IT integration of the supply chain among SMEs. These results could be evidence of the difficulties for SMEs in adopting IT in their integration with suppliers and clients. As noted by Stefansson (2002), Eagan, Clancy and O'Toole

ISSN: 07 I8-2724. (http://www.jotmi.org)

Journal of Technology Management \& Innovation (c) Universidad Alberto Hurtado, Facultad de Economía y Negocios. 
(2003) and Bayraktar et al (2009), one of the main difficulties is the high cost of implementing these technologies, which can result in the loss of competitiveness by SMEs (Kauremaa, Kärkkäinen and Ala-Risku, 2009).

Equally, the results presented indicate that integration into the supply chain through intra-organizational IT is related to some types of innovation among the studied SMEs. Some internal practices that suppose exchange of information with partners, as is the case of "the use of IT to design prototypes" and "the use of IT in production" show favoring innovation in the group of SMEs that present innovation simultaneously in products and processes and in the group that innovates in products. Although insipient, these results indicate that the use of IT in the internal context can make a contribution to innovation, as suggested by Redoli et al (2008), Drayse (20II) and Rochina-Barrachina, Mañez and Sanchis-Llopis (20I0). From the SCM perspective, the efforts of SMEs to integrate with their suppliers and clients, based on the management of some internal functions of the supply chain that are associated with the production process (Bayraktar et al, 2009).

\section{Conclusions}

This research discusses the support of SCM practices to the innovation of products and processes in SMEs. Assuming the relationships of dependence of these enterprises in a chain led by large clients, the discussion can be extended to reflect this dependence in the relationship of SMEs with their suppliers. In this context, the impact of the interactions of these enterprises with both agents (clients and suppliers) in innovation is verified. This study contributes in order to increase the number of studies about SCM practices in SMEs, carried out by other researchers worldwide (Kauremaa, Kärkkäinen and Ala-Risku, 2009; Huin, Luong and Abhary, 2002; Quayle, 2006; Bhutta, Rana and Asad, 2007; Bayraktar et al, 2009; Chung and Kim, 2003; Welker, Van der Vaart and Van Donk, 2008; Arend and Wisner, 2005; Koh et al, 2007; Cambra-Fierro and Polo-Redondo, 2008; Bordonaba-Juste and Cambra-Fierro, 2009; Johnsen and Ford, 2006; Williams, 2006; Pagell, 2004; Kaminski, Oliveira and Lopes, 2008), and provide some contributions to the existing literature.

First, it provides some positive evidence of the support that SCM provides to innovation of products and processes in SMEs, a relationship that has not been greatly explored in the literature. In general, the literature about innovation in SMEs reiterates that vertical cooperation with clients and suppliers plays an important role in this process (Zeng, Xie and Tam, 20 10; Doloreux, 2004;Abereijo et al., 2009; Bigliardi, Colacino and Dormio, 20I I). However, few studies have employed the perspective of SCM in this context. Although results are insipient in terms of the relationship between both constructs (e.g. SCM and innovation), the positive evidence of these relationships makes this study one of the first comprehensive steps towards verifying the importance of SCM practices for innovation processes in SMEs.

Secondly, to obtain some evidence similar to previous studies about the importance of the relationship with clients and suppliers for innovation (Kaufmann and Tödtling, 2002; Kaminski, Oliveira and Lopes, 2008; Chung and Kim, 2003; Doloreux, 2004; Wang and Kafouros, 2009), gaps are evidenced in the integration between suppliers and clients. For instance, the possible dependence on large clients (evidenced by the concentration of sales in only one client as shown in Graph 2) reveals deficient integration into the chain, in which the suppliers of SMEs do not appear as agents of collaboration that contribute significantly to the exchange ideas and processes for innovation. In this sense, dependence on clients can impose practices of integration for SMEs, such as the adoption of intra- and inter-organizational IT (De Toni, Nassimbeni and Tonchia, 1995; Gélinas and Bigras, 2004). This does not, in turn, extend SCM practices to suppliers. These imperfections can indicate the lack of understanding of the logic of SCM or difficulties and limitations to enter this logic, which can imply lower performance (Arend and Wisner, 2005). Furthermore, the scarcity of resources for SMEs to embrace IT must be considered as one of the possible factors impeding an efficient SCM (Stefansson, 2002; Eagan, Clancy and O'Toole, 2003; Bayraktar et al, 2009).

Thirdly, considering the context of adopting intra- and interorganizational IT, this work contributes to previous studies by evidencing the gaps in the integration of operations in the supply chain and the flow of information among agents and also internally. For Kauremaa, Kärkkäinen and Ala-Risku, (2009), Bayraktar et al (2009) and Hafeez et al (2010), SMEs present internal and external barriers to the use of information systems, among these are notably scarce resources and the lack of abilities in the use of IS as a support to SCM. The findings of this study seem to show this lack of abilities in the adoption of IT. For example, in the adoption of IT in internal processes, the results do not reveal any relation between the exchange of information among departments of the enterprise and innovation and, in some cases, negative associations reveal contradictory results from the perspective of SCM. Considering that the basis of management is the flow of information between clients and suppliers this can favor the adaptation or creation of new products and services according to the client's needs. From this perspective of innovation in SMEs, it is expected that the flow of information between clients and suppliers promotes interaction among agents, which can contribute to the generation of innovative projects (Kaminski, Oliveira and Lopes, 2008). On the one hand, the results found in this research follow this logic and evidence that some internal practices suppose the external 
exchange of information with partners favors innovation in the group of SMEs that present simultaneous innovation in products and processes and in the group that innovates in products. On the other hand, there are some gaps in these links. This can show that communications are more informal and are not absorbed strategically to contribute to innovation (Kauremaa, Kärkkäinen and Ala-Risku, 2009).

Finally, this study reveals a specific context of analysis of phenomena. As Chow et al (2008) notes, the practice and structure of SCM can depend on the situation in which it is applied, given that each country has its perception as to how efficiently the supply chain is managed. From this perspective, SMEs in northern Chile bring together the favorable characteristics of the openness of the country to international trade and its sophisticated business context. The macroeconomic stability and the high level of infrastructure development create a positive environment for SMEs to incorporate new technologies and obtain a competitive position in the supply chain. In addition, the importance of the mining sector to the Chilean economy and the country's leading position on cooper exports suggests advantages for SMEs in their interactions with large multinational enterprises that have installed operations in northern Chile. These advantages are represented by accessing new technologies, knowledge, new markets and new customers by the agreements established with large firms (Kennel, 2007). Innovation is a consequence of these interactions (Doloreux, 2004), and is intensified by regional proximity (Idrissia, Amaraa and Landrya, 20I2). As noted by Jiménez (2005), the voluntary agreements among firms, associations of firms and government facilitate the initiatives for incremental innovations in Chilean SMEs (Jiménez, 2005).

However, it remains an open question whether the SMEs are taking full advantage of this openness and of the technologies and knowledge generated by the interactions with large firms. The partial affirmations of the hypotheses presented reveal that the deficiencies in the integration of SMEs in SCM can raise difficulties in the exchange of technology and be resulting in poorer performances than what can potentially be expected. From this perspective, although high cost is one of the main reasons that SMEs fail to embrace IT initiatives that could favor their integration with their clients (Stefansson, 2002), it is expected that the favorable context of opening the country will facilitate exchange among the agents in the supply chain.

\section{Managerial Implications}

The results of this study emphasize the importance of SCM practices for innovation in products and processes in SMEs. The gaps found in the process of integration between large clients and SME suppliers and, for their part, between SMEs and their suppliers, have implication for both SMEs themselves and for regional governments.

In the context of SMEs, while on the one hand dependence on large clients is positive in terms of developing innovations, on the other hand it appears to monopolize the attention of SMEs. This can generate difficulties for these enterprises in their integration with suppliers. Considering that integration in the supply chain represents cost efficiency and important competitive advantages, not inserting suppliers in this logic can imply poorer performance for SMEs and limitations in processes of innovation.

As evidenced in this study, the use of IT in internal functions related to SCM or in activities of interaction with agents provides some support to innovation. Such support can be more representative to the degree that SMEs increase the use of IT in the supply chain, which leads to generating an environment more conducive to collaboration by means of exchange and the diffusion of ideas and knowledge among the agents (Kaminski, Oliveira and Lopes, 2008; Macpherson, Jones and Zhang, 2005). On the one hand, collaboration of SMEs with their main clients involves the use of inter-organizational systems for communication and the evolution of these relationships depends on the adoption of technologies on the part of the SMEs (Boeck, Bendavid and Lefebvre, 2009). On the other hand, the suppliers of SMEs depend on the flow of information derived from demand to know the needs of the clients in terms of products and services. Thus, by adopting IT in the internal and external processes, can benefit SMEs, on the one hand, through reduced operative costs and grater agility in the transmission of information to their suppliers, and on the other hand, through providing unique products and services to their clients, generating sustainable competitive advantages over time.

In the public sphere, this study contributes to the development of public policies oriented to strengthening SMEs in their relationships with large clients, in relation to investment in IT and the definition of strategies that translate into mutual benefits all along the supply chain. Essentially, the contribution is the generation of information with regard to the relationships established between SMEs, large clients and suppliers, and the gaps evidenced in these interactions. This raises the question of the regional policies of the Chilean government, which is defining and implementing policies to improve competitiveness of small and mediumsized enterprises in relation to development and knowledge management, articulation with their surroundings and internationalization (CORFO, 2007). The strategic orientation of these policies lies in improving managerial skills, innovation capabilities, and the internationalization of SMEs in the mining sector. In this sense, the objective of the government program is to offer support and resources to strengthen 
the positioning of firms in the productive chain, as well as to promote initiatives for innovation to generate added value and sustainable competitive advantages for SMEs. The evidence presented in this study reinforces the notion that effective supply chain management, which includes collaborative practices and IT integration with suppliers and clients, would enable enterprises to improve their performance in innovation. Supply chain practices tend to influence innovation positively. Public politics need to focus attention on developing such practices.

\section{Limitations and Future Research Directions}

This study was limited to the relations between SCM practices and innovation. Subsequent research could consider performance as a final variable of the impact of these relationships. As evidenced in the majority of studies about SCM, this practice contributes to improving performance and it would be interesting to verify to what point this positive influence is intensified when the innovation is included in the analysis.

Also, this research did not go deeply into identifying the nature of inter-organizational IT practices among SMEs and their clients and suppliers. As noted by Kauremaa, Kärkkäinen and Ala-Risku (2009), many SMEs do not use system-tosystem integration to interchange data with their partners. On the contrary, people are involved in some part of this interchange, which can generate poor performance for SMEs. Future research could identify the level of sophistication of IT among SMEs, relating this to the variables proposed in this work, which could contribute to a better understanding of the results.

\section{References}

ABEREIJO, I. O., Adegbite, S. A., liori, M. O. Adeniyi, A. A., Aderemi, H.A. (2009). Technological innovation sources and institutional supports for manufacturing small and médium enterprises in Nigeria. Journal of Technology Management \& Innovation, 4(2), 82-89.

AREND, R.J. Wisner, J. D. (2005). Small business and supply chain management: is there a fit? Journal of Business Venturing, 20, 403-436.

BAYRAKTAR, E., Demirbag, M., Koh, S.C.L., Tatoglu, E., Zaim, H. (2009). A causal analysis of the impact of information systems and supply chain management practices on operational performance: evidence from manufacturing SMEs in Turkey, International Journal of Production Economics, 122, I33-149.

BAYRAKTAR, E., Gunasekaran, A., Koh, S. C. L., Tatoglu, E., Demirbag, M., Zaim, S. (2010). An efficiency comparison of supply chain management and information systems practic- es: a study of Turkish and Bulgarian small and medium sized enterprises in food products and beverages, International Journal of Production Research, 48(2), 425-45I.

BIGLIARDI, B., Colacino, P., Dormio, A. J. (20I I). Innovative characteristics of small and medium enterprises. Journal of Technology Management \& Innovation, 6(2), 83-93.

BOECK, H., Bendavid, Y., Lefebvre, E. (2009). Evolving B2B ecommerce adaptation for SME suppliers, Journal of Business \& Industrial Marketing, 24(8), 56I-574.

BORDONABA-JUSTE,V., Cambra-Fierro, J.J. (2009). Managing supply chain in the context of SMEs: a collaborative and customized partnership with the suppliers as the key for success, Supply Chain Management:An International Journal, 14(5), 393-402.

BOS-BROUWERS, H. E. J. (2010). Corporate sustainability and innovation in SMEs: evidence of themes and activities in practice, Business Strategy and the Environment, 19, 4I7435.

BHUTTA, M. K. S., Rana, A. I., Asad, U. (2007). SCM practices and the health of the SMEs in Pakistan, Supply Chain Management:An International Journal, I2(6), 4I2-422.

BUNNELL,T. G., Coe, N. M. (200I). Spaces and scales of innovation, Progress in Human Geography, 25, 569-589.

CAMBRA-FIERRO, J. J., Polo-Redondo, Y. (2008). Long-term orientation of the supply function in the SME context: reasons, determining factors and implications. International Small Business Journal, 26(5), 619-646.

CHOW,W.S., Madu, C. N., Kuei, C. H., Lu, M. H., Lin, C., Tseng, H. (2008). Supply chain management in the US and Taiwan: an empirical study, Omega, 36(5), 665-679.

COYLE, J. J., Bardi, E., Langley, C. J. (2003). The management of business logistics: a supply chain perspective. Thompson Learning, Canada.

CORBETT, C. J., Blackburn, J. D., Wassenhove, L. N.V. (1999). Case study: partnerships to improve supply chains, Sloan Management Review, 40(4), 7I-82.

CHUNG, S., Kim, G. M. (2003). Performance effects of partnership between manufacturers and suppliers for new product development: the supplier's standpoint. Research Policy, 32(4), 587-603.

CHURCHILL, G. A. (1979). A paradigm for developing better measures of marketing constructs, Journal of Marketing Research, 16, 64-73. 
CORFO (2007). Programa territorial integrado: servicios especializados para el cluster minero, Dirección Regional

CORFO, Región de Antofagasta.

DAMASKOPOULOS, P., Evgeniou,T. (2003).Adoption of new economy practices in SMEs in Eastern Europe, European Management Journal, 2I (2), I33-I45.

DE TONI, A., Nassimbeni, G., Tonchia, S. (1995). Small local firms inside the supply chain: challenges and perspectives, Small Business Economics, 7, 24I-249.

DEWICK, P., Miozzo, M. (2004). Networks and innovation: sustainable technologies in Scottish social housing, R\&D Management, 34(3), 323-333.

DOLOREUX, D. (2004). Regional networks of small and medium sized enterprises: evidence from the metropolitan area of Ottawa in Canada, European Planning Studies, 12(2), 173-189.

DRAYSE, M. H. (20I I). Globalization and innovation in a mature industry: furniture manufacturing in Canada, Regional Studies, 45(3), 299-3I8.

EAGAN, T., Clancy, S., O'Toole, T. (2003). The integration of e-commerce tools into the business processes of SMEs, Irish Journal of Management, 24, I39-I53.

GÉLINAS, R., Bigras, Y. (2004). The characteristics and features of SMEs: favorable or unfavorable to logistics integration?, Journal of Small Business Management, 42(3), 263-278.

GUNASEKARAN, A., Patel, C., McGaughey, R. E. (2004). A framework for supply chain performance measurement, International Journal of Production Economics, 87, 333-347.

HAFEEZ, K., Keoy, K. H. A., Zairi, M., Hanneman, R., Koh, L. (20I0). E-supply chain operational and behavioral perspectives: an empirical study of Malaysian SMEs, International Journal of Production Research, 48(2), 525-546.

HAIR, J. F., Anderson, R. E., Tatha, R. L., Black, W. C. (1999). Análisis multivariante, Prentice Hall Iberia, Madrid.

HARTLEY,J. L., Zirger, B.J., Kamath, R. R. (1997). Managing the buyer-supplier interface for on-time performance in product development, Journal of Operations Management, I5(I), 5770.

HUIN, S. F., Luong, L. H. S., Abhary, K. (2002). Internal supply chain planning determinants in small and medium-sized manufacturers, International Journal of Physical Distribution and Logistics Management, 32(9), 77I-782.
IDRISSIA, M. O.,Amaraa, N., Landrya, R. (2012). SMEs' degree of openness: the case of manufacturing industries. Journal of Technology Management \& Innovation, 7(I), I87-2I0.

JIMÉNEZ, O. (2005). Innovation-oriented environmental regulations: direct versus indirect regulations; an empirical analysis of small and medium-sized enterprises in Chile, Environment and Planning A, 37, 723-750.

JOHNSEN, R. E., Ford, D. (2006). Interaction capability development of smaller suppliers in relationships with larger customers, Industrial Marketing Management, 35, I002- 1015.

KABANDA, G. (2008). Collaborative opportunities for ICTs development in a challenged African environment. Journal of Technology Management \& Innovation, 3(3), 91-99.

KAMINSKI, P. C., Oliveira, A. C., Lopes, T. M. (2008). Knowledge transfer in product development processes: a case study in small and medium enterprises (SMEs) of the metalmechanic sector from São Paulo, Brazil, Technovation, 28, 29-36.

KAUFMANN,A.,Tödtling, F. (2002). How effective is innovation support for SMEs? An analysis of the region of Upper Austria, Technovation, 22, I47-I59.

KAUREMAA, J., Kärkkäinen, M., Ala-Risku, T. (2009). Customer initiated interorganizational information systems: the operational impacts and obstacles for small and medium sized suppliers, International Journal of Production Economics, I1 19, 228-239.

KENNEL, J. S. (2007). Foreign direct investment and local linkages: an empirical investigation, Management International Review, 47(I), 5I-77.

KIM, S.W. (2006). Effects of supply management practices, integration and competition capability on performance, Supply Chain Management:An International Journal, I I (3), 24I-248.

KIM, S.W. (2009). An investigation on the direct and indirect effect of supply chain integration on firm performance. International Journal of Production Economics, I I 9, 328-346.

KOH, L. S. C., Demirbag, M., Bayraktar, E., Tatoglu, E., Zaim, S. (2007). The impact of supply chain management practices on performance of SMEs, Industrial Management \& Data Systems, I07(I), I03-124.

LAMBERT, D. M., Cooper, M. C. (2000). Issues in supply chain management, Industrial Marketing Management, 29(I), 65-83.

LEVY, M., Powell, P., Yetton, P. (2002). The dynamics of SME information systems, Small Business Economics, 19, 34I-354.

ISSN: 07 I8-2724. (http://www.jotmi.org)

Journal of Technology Management \& Innovation @ Universidad Alberto Hurtado, Facultad de Economía y Negocios. 
LI, G., Yang, H., Sun, L., Sohal, A. (2009). The impact of IT implementation on supply chain integration and performance. International Journal of Production Economics, I 20, I 25- I 38.

LIN, B.W., Chen, J. S. (2005). Corporate technology portfolios and R\&D performance measures: a study of technology intensive firms, R\&D Management, 35(2), I57- 170.

MACPHERSON, A., Jones, O., Zhang, M. (2005). Virtual reality and innovation networks: opportunity exploitation in dynamic SMEs, International Journal of Technology Management, 30(I/2), 49-66.

MENTZER, J.T., Gundlach, G. (20I0). Exploring the relationship between marketing and supply chain Management: introduction to the special issue, Journal of the Academy of Marketing Science, 38, I-4.

MENTZER, J.T., Dewitt,W. J., Keebler, J. S., Min, S., Nix, N.W., Smith, C. D., Zacharia, Z. G. (200I). Defining supply chain management, Journal of Business Logistics, 22(2), I-26.

OECD (2005). Manual de Oslo: guía para la recogida e interpretación de datos sobre innovación. OECD/Eurostat, Paris [Spanish version].

PAGELL, M. (2004). Understanding the factors that enable and inhibit the integration of operations, purchasing and logistics, Journal of Operations Management, 22(5), 459-487.

PETERSEN, K. J., Handfield, R. B., Ragatz, G. L. (2005). Supplier integration into new product development: coordinating product, process and supply chain design, Journal of Operations Management, 23(3-4), 37I-388.

QUAYLE, M. (2003). A study of supply chain management practice in UK industrial SMEs, Supply Chain Management: An International Journal, 8(I), 79-86.

RAJESH, R., Pugazhendhi, S., Ganesh, K., Muralidharan, C., Sathiamoorthy, R. (20II). Influence of 3PL service offerings on client performance in India,Transportation Research Part E, 47, I49-I65.

REDOLI, J., Mompó, R., García-Díez, J., López-Coronado, M. (2008). A model for the assessment and development of internet-based information and communication services in small and medium enterprises, Technovation, 28, 424-435.

RENNINGS, K., Rammer, C. (20I I).The impact of regulationdriven environmental innovation on innovation success and firm performance, Industry and Innovation, I8(3), 255-283.

ROCHINA-BARRACHINA, M. E., Mañez,J.A., Sanchis-Llopis, J.A. (2010). Process innovation and firm productivity growth, Small Business Economics, 34, I47-166.
SORIANO, D. R., Roig, S., Sanchis, J. R., Torcal, R. (2002). The role of consultants in SMEs, International Small Business Journal, 20(I), 95-103.

SRIVASTAVA, R. K., Shervani, T.A., Fahey, L. (1999). Marketing, business processes, and shareholder value: an organizationally embedded view of marketing activities and the discipline of marketing, Journal of Marketing, 63(3), I68- I79.

STEFANSSON, G. (2002). Business-to-business data sharing: a source for integration of supply chains, International Journal of Production Economics, 75(I-2), I35-I 46.

STOCK, J. R., Boyer, S. L., Harmon, T. (20 I0). Research opportunities in supply chain management, Journal of the Academy of Marketing Science, 38, 32-4I.

THEINSATHID, P., Chandrachai, A., Keeratipibul, S. (2009). Managing bioplastic business innovation in start up phase. Journal of Technology Management \& Innovation, 4(I), 82-93.

TOWERS, N., Burnes, B. (2008). A composite framework of supply chain management and enterprise planning for small and medium-sized manufacturing enterprises, Supply Chain Management:An International Journal, I3(5), 349-355.

VERHEES, F. J. H. M., Meulenberg, T. G. (2004). Market orientation, innovativeness, product innovation, and performance in small firms, Journal of Small Business Management, 42(2), I34-I54.

ZENG, S. X., Xie, X. M., Tam, C. M. (20I0). Relationship between cooperation networks and innovation performance of SMEs, Technovation, 30, I8I-194.

WANG, C., Kafouros, M. I. (2009). What factors determine innovation performance in emerging economies? Evidence from China, International Business Review, 18, 606-616.

WELKER, G. A., Van der Vaart, T.,Van Donk, D. P. (2008). The influence of business conditions on supply chain information-sharing mechanisms: a study among supply chain links of SMEs, International Journal of Production Economics, I I 3 , 706-720.

WHITLEY, R. (2002). Developing innovative competences: the role of institutional frameworks, Industrial and Corporate Change, I I (3), 497-528.

WILLIAMS, S. J. (2006). Managing and developing suppliers: can SCM be adopted by SMEs? International Journal of Production Research, 44(I8-19), 383 I-3846.

ISSN: 07I 8-2724. (http://www.jotmi.org)

Journal of Technology Management \& Innovation (c) Universidad Alberto Hurtado, Facultad de Economía y Negocios. 
J.Technol. Manag. Innov. 2012,Volume 7, Issue 3

ISSN: 07I8-2724. (http://www.jotmi.org)

Journal of Technology Management \& Innovation @ Universidad Alberto Hurtado, Facultad de Economía y Negocios. 